\title{
Evaluation of the relationship between perception of tobacco packaging pictorial warnings and the nicotine addiction levels of smokers who admitted to smoking cessation clinic in Malatya, Turkey
}

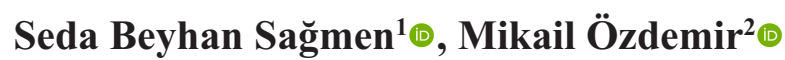 \\ ${ }^{1}$ Department of Pulmonary Medicine, Malatya State Hospital, Malatya, Turkey \\ ${ }^{2}$ Department of Public Health, Osmaniye Province Health Administration, Osmaniye, Turkey
}

DOI: $10.18621 /$ eurj.381904

\begin{abstract}
Objective: In this study, we aimed to investigate relationship between perception of tobacco packaging pictorial warnings and the nicotine addiction levels of smokers who admitted to smoking cessation clinic in Malatya, Turkey.

Methods: Three hundred fifty-six patients were enrolled from the Malatya State Hospital Smoking Cessation Clinic. The characteristics of the patients, and number of cigarettes smoked were evaluated. The Fagerström test for nicotine dependence was used. Fourteen of the best-known and most effective pictorial health warnings on cigarette packages were shown and evaluated.

Results: The two best-known pictorial warnings in both male and female participants were pictorial 6, "Smoke contains benzene, nitrosamines, formaldehyde, and hydrogen cyanide" and pictorial 7, "Smoking causes fatal lung cancer". The third best-known pictorial warning for female was pictorial 4, "Smokers die younger," and for male it was pictorial 1, "Smoking may reduce blood flow and causes impotence". Female were most affected by pictorial 11, "Protect children; don't make them breathe your smoke", and male were most affected bypictorial 1, "Smoking may reduce blood flow and causes impotence" ( $p<0.043$ and $p=0.01$, respectively). Fagerström scores compared with pictures mostly known and affected by participants, the highest and lowest scores belongs to same pictures; the highest Fagerström score was $8.29 \pm 2.14$ for best known and $8.25 \pm 2.19$ for most affected picture is number 2; the lowest Fagerström score was $6.46 \pm 2.55$ for best known and $6.56 \pm$ 2.68 for most affected picture is number 3 .
\end{abstract}

Conclusion: The effect of pictures about the decision to quit smoking may be investigated by a qualitative study especially for pictures $1,2,4,6,7$, and 11 .

Keywords: pictorial health warnings, smoking cessation, cigarette, tobacco

Received: January 20, 2018; Accepted: June 17, 2018; Published Online: June 25, 2018

S moking is among the worst public health problems of Turkey. As is the case in the entire world, smoking is a widespread and considerable public health problem. Approximately one fifth of the world's population smokes and about 6 million people die every year due to tobacco use. According to

Address for correspondence: Seda Beyhan Sağmen, MD., Malatya State Hospital, Department of Pulmonary Medicine, Malatya, Turkey E-mail: sedabeyhan05@yahoo.com 
estimations, this figure is expected to reach 10 million in $2020[1,2]$.

Today, over $80 \%$ of smokers start smoking when they are aged younger than 18 years [3]. There are various methods for the purposes of educating society on the detriments caused by smoking. One of the most cost effective measures is printing warning messages on cigarette packages; because a person who smokes a pack of cigarettes every day must see the packaging more than 7000 times a year.

First, written warnings were printed on packs. Later, assuming that pictorial warnings could be much more effective, pictorials emphasizing the detriments were included. Warning messages were first written on cigarette packs in 1965, and pictorial health warnings were first used on cigarette packsin Canada in 2001 [4]. There are legal sanctions and measures against cigarette use in Turkey. The World Health Organization's MPOWER pack, which has a considerable place with regard to smoking control, includes essential applications such as preventing passive smoking, providing support to smokers to stop smoking, increasing taxes, banning advertising or promotion of tobacco products, training and warning society as to the detriments of tobacco products. It also aims to monitor and evaluate smoking control process.

There are various applications for the purposes of educating society on the detriments of smoking. One of the most significant and effective applications is inclusionof pictorial warning messages on cigarette packs because they are much more effective than text alone. Printed and pictorial messages on cigarettepacks were obligatory in Turkey as of 2011 $[5,6]$.

In this study, we evaluated relationship between perception of tobacco packaging pictorial warnings and the nicotine addiction levels of smokers who admitted to smoking cessation clinic in Malatya, Turkey.

\section{METHODS}

The study was conducted on 356 patients who attended the Malatya State Hospital Smoking Cessation Clinic. Patients who presented to the clinic between March 2015 and July 2015 were shown the 14 pictorial warnings and questioned as to which was the best known, and which one led them to apply to the Smoking Cessation Clinic. The study included an initial screening using a structured self-administered questionnaire used to collect the following information: socio-demographic variables including age, gender, and education. The degree of nicotine dependence was assessed at baseline with the Fagerström test of nicotine dependence (FTND) consisting of six questions designed to measure tobacco dependence, which predicts smoking cessation and includes components of cigarette consumption and its typology. Typology has been

Tablo 1. Demographic variables of participants

\begin{tabular}{llcc}
\hline & & $\mathbf{n}$ & $\mathbf{\%}$ \\
\hline Gender & Women & 111 & 31.2 \\
Age & Men & 245 & 68.8 \\
& $\leq 20$ & 17 & 4.8 \\
& $21-30$ & 104 & 29.2 \\
& $31-40$ & 113 & 31.7 \\
& $41-50$ & 76 & 21.3 \\
Education Status & $51-60$ & 30 & 8.4 \\
& $>60$ & 16 & 4.5 \\
& Did not finish any school & 3 & 0.8 \\
& Primary education & 114 & 32 \\
& Secondary education & 89 & 25 \\
& University & 139 & 39 \\
& Master Degree & 11 & 3.1 \\
& & 356 & 100. \\
\hline
\end{tabular}




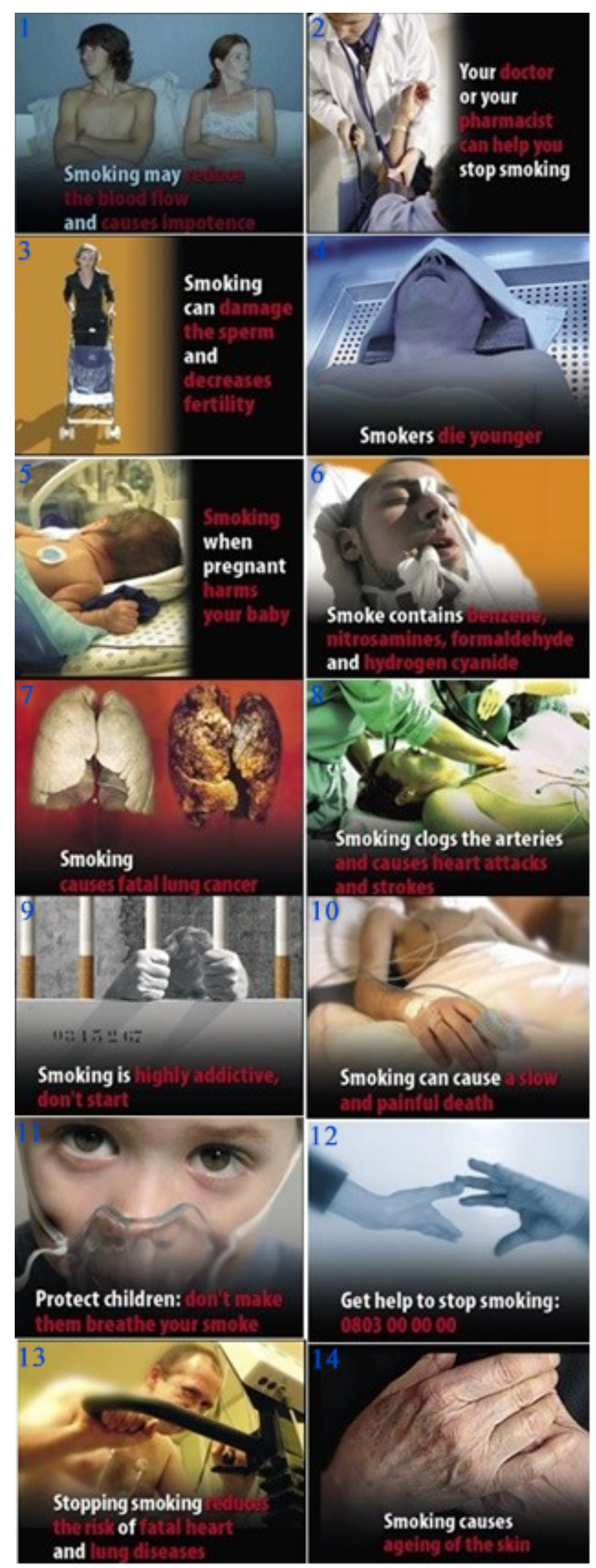

Figure 1. The best known warnings among men and women. constructed to describe smokers according to when and why they smoke and their capability to refrain from smoking. The FTND score can range from 0 to 10 point with a score of $0-2$ indicate minimum nicotine dependence whereas a score of 8-10 indicate very high dependence.

\section{Statistical Analysis}

Statistical analyzes were performed using the SPSS version 15.0 program. Normal distribution of variables was examined by histogram graphs and Kolmogorov-Smirnov test. Nominal variables were compared with Pearson Chi Square and Fisher's Exact Tests. Statistically significant results were obtained when the $\mathrm{p}$ value was below 0.05 .

\section{RESULTS}

One hundred ten female and 246 male applied to the Malatya State Hospital Smoking Cessation Clinic and were included in the study. The average age of the patients was 35 years (range, 14 to 75 years); the average smoking period was 16 years (range, 2 to 55 years). The sociodemographic characteristics of the participants are shown in Table 1.

Forty-two percent of the group were university graduates, and the remaining 58\% were high school or primary school graduates. The two best-known pictorial warning were pictorial 6 , "Cigarette smoke contains carcinogens such as benzene nitrosamine, formaldehyde, and hydrogen cyanide" (female/male: $21.9 \% / 22.2 \%$ ) and pictorial 7, "Smoking causes fatal lung cancer" (female/male: $20.4 \% ; 20 \%$ ). The third best known for female was "Smokers die younger" $(12.6 \%)$, and for male it was pictorial 1, "Smoking reduces blood flow and causes impotence" (16.7\%) (Figure 1). Pictorial 11, "Protect your children; don't make them breathe your smoke" mostly affected female, and pictorial 1, "Smoking reduces blood flow and causes impotence" mostly affected male $(p<$ 0.043 and $p=0.01$, respectively) (Figure 2).

When Fagerström scores compared with pictures mostly known and affected by participants, the highest and lowest scores belongs to same pictures; the highest Fagerströmscore was $8.29 \pm 2.14$ for best known and $8.25 \pm 2.19$ for most affected picture is number 2 ; the lowest Fagerström score was $6.46 \pm 2.55$ for best 

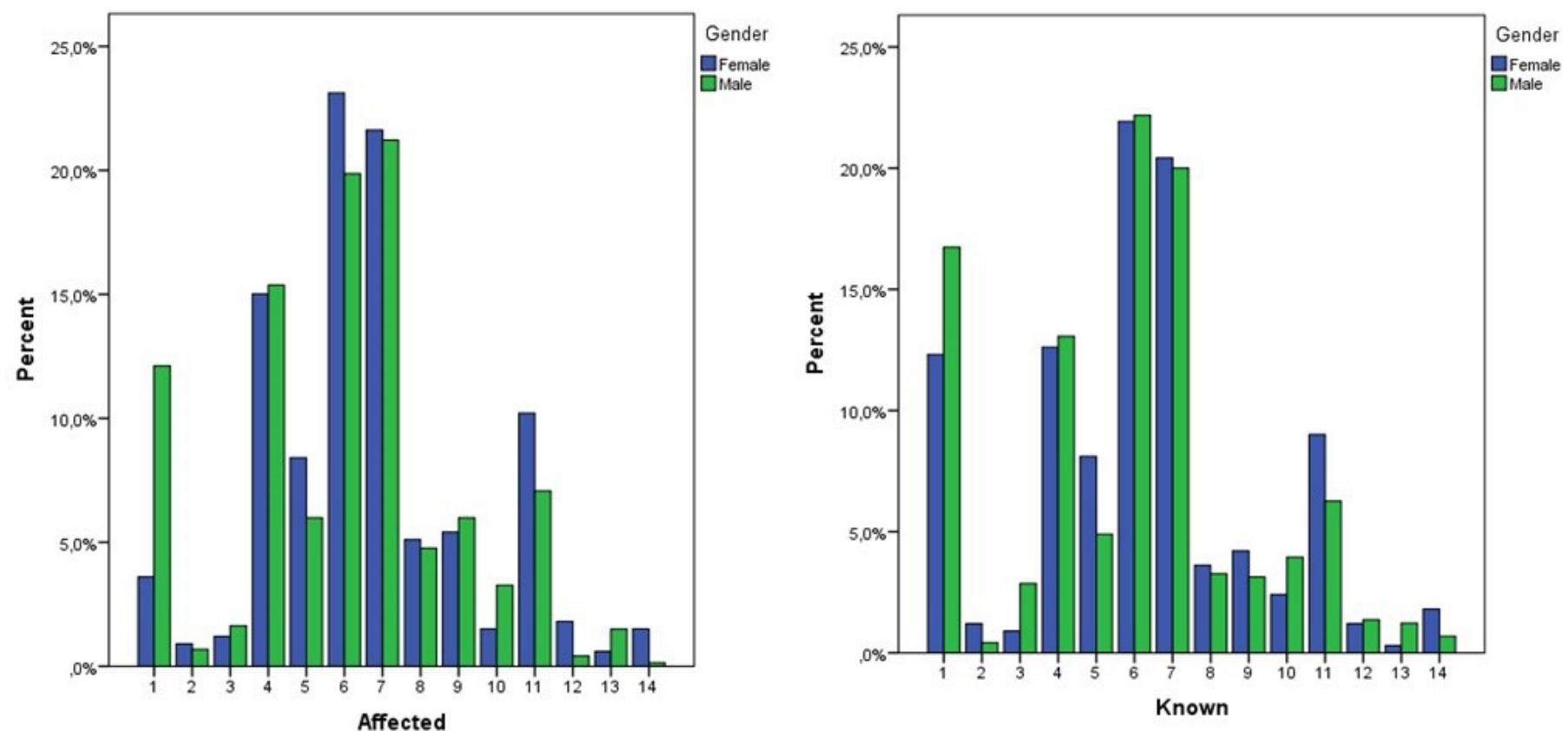

Figure 2. The most impactful pictorial warnings among men and women.

Tablo 2. Fagerström scores for mostly known pictures

\begin{tabular}{lc}
\hline $\begin{array}{l}\text { Picture } \\
\text { Number }\end{array}$ & $\begin{array}{c}\text { Fagerström Scores } \\
(\text { Mean } \pm \text { SD) }\end{array}$ \\
\hline 1 & $7.19 \pm 2.10$ \\
2 & $8.29 \pm 2.14$ \\
3 & $6.46 \pm 2.55$ \\
4 & $6.86 \pm 2.39$ \\
5 & $6.89 \pm 2.26$ \\
6 & $6.86 \pm 2.29$ \\
7 & $7.05 \pm 2.26$ \\
8 & $7.06 \pm 2.43$ \\
9 & $6.65 \pm 2.56$ \\
10 & $7.11 \pm 2.27$ \\
11 & $6.83 \pm 2.02$ \\
12 & $7.50 \pm 2.50$ \\
13 & $7.00 \pm 2.45$ \\
14 & $7.55 \pm 1.57$ \\
\hline
\end{tabular}

known and $6.56 \pm 2.68$ for most affected picture is number 3 (Tables 2 and 3).

\section{DISCUSSION}

Printing warning messages on tobacco product packaging is a cost effective approach. This is also referred to in the Tobacco Control Frame Agreement as MPOWER Pack [7, 8]. Smokers and non-smokers see such messages. At the beginning, only pictorials
Tablo 3. Fagerström scores for mostly affected pictures

\begin{tabular}{lc}
\hline $\begin{array}{l}\text { Picture } \\
\text { Number }\end{array}$ & $\begin{array}{c}\text { Fagerström Scores } \\
\text { (Mean } \pm \text { SD) }\end{array}$ \\
\hline 1 & $7.30 \pm 2.26$ \\
2 & $8.25 \pm 2.19$ \\
3 & $6.56 \pm 2.68$ \\
4 & $6.91 \pm 2.23$ \\
5 & $6.81 \pm 2.29$ \\
6 & $6.78 \pm 2.34$ \\
7 & $7.07 \pm 2.21$ \\
8 & $7.15 \pm 2.43$ \\
9 & $6.94 \pm 2.25$ \\
10 & $7.03 \pm 2.51$ \\
11 & $6.70 \pm 2.03$ \\
12 & $8.00 \pm 2.45$ \\
13 & $7.69 \pm 1.97$ \\
14 & $7.17 \pm 1.72$ \\
\hline
\end{tabular}

that referred to problems caused by smoking were printed. This was anappropriate method because it was more efficient. In addition, they caught the attention of illiterate smokers. Pictorial warning messages were first printed on cigarette packs in 2001.

In our study, the two pictorial warnings most recognized by female and male were "Cigarette smoke contains carcinogens such as benzene nitrosamine, formaldehyde, and hydrogen cyanide" and "Smoking causes fatal lung cancer". With regard to impression, female were most impressed by the message "Protect 
your children; do not make them breathe your smoke", and male were most affected by "Smoking reduces blood flow and causes impotence".

In a study performed on high school graduates, likewise, male students stated that they were particularly affected by the impotence effect of smoking. Impotence is important for male. Female students mostly refer to the importance of smoking during pregnancy because of its effect on unborn babies. This shows that females and males pay attention to different subjects. On the other hand, both male or female students found the lung cancer warning most striking [9]. Lung cancer is a feared complication due to its fatality rate.

Providing awareness of the detrimental effects of smoking using pictorial warnings is an influential method. Supporting photos carrying clear messages that reflect serious health problems would be a good educational practice. Current pictorials have not been found sufficient by high school students.

In the study by Vardavas et al. [10], the pictorial and notice with strongest warning was mostly "Smoking causes fatal lung cancer" with a frequency of $38.0 \%$, followed by "Smoking is detrimental to your unborn baby" at $11.7 \%$, and "Protect your children; do not make them breathe your smoke" with 6.6\% (10). In a Turkish study by Bayrak et al. [11], the most influential warning message was "Smoking is detrimental to your unborn baby" with a rate of $70.6 \%$, which proves that different pictorials and notes could have differing effects on different social groups.

With regard to tobacco control, cigarette packs could be an efficient tool to transmit information on the detrimental effect of smoking. They will be particularly effective among people with poor literacy and children. The more cigarette packs there are, the better the message is received. The findings to date show that pictorial warnings notify people better about health risks, provide high awareness and visibility between non-smokers and youths, and clarify health risks, as such, they are much more effective than written warnings or notices alone.

Studies also show that regularly updating pictorial warnings on cigarette packs and making them large and striking would make them persuasive, and provide public support, medical information, and motivation to quit smoking [12]. Another study in Mexico found that pictorial warnings hada more positive effect than written ones [13].

As with our study, another study reported that people with lower education were more prone to addiction. This might be both due to lack of education or assuming cigarette smoking as a relief method while coping with difficulties. In the same study, no differences was observed in Fagerström scores in relation with the participants' sex [14]. On the contrary, in our study, Female were significantly more dependent than male according to statistical estimations.

\section{CONCLUSION}

Pictorial warnings on the cigarette packs are very influential for the purposes of establishing social awareness in the challenge against smoking. For Turkey, reinforcing written warning messages on cigarette packs with pictorials is an important development. This study is a precursor of detailed research about relation between smoking cessation and pictorial warnings. At the end of this study, the effect of pictures about the decision to quit smoking may be investigated by a qualitative study especially for pictures $1,2,4,6,7$, and 11 .

\section{Authorship declaration}

All authors listed meet the authorship criteria according to the latest guidelines of the International Committee of Medical Journal Editors, and all authors are in agreement with the manuscript.

\section{Conflict of interest}

The authors disclosed no conflict of interest during the preparation or publication of this manuscript.

\section{Financing}

The authors disclosed that they did not receive any grant during conduction or writing of this study.

\section{REFERENCES}

[1] Bala MM, Strzeszynski L, Topor-Madry R, Cahill K. Mass media interventions for smoking cessation in adults. Cochrane Database Syst Rev 2013;6:CD004704.

[2] Mackay J, Eriksen M, Shafey O. The Tobacco Atlas. 2nd ed. 
Brighton, UK: American Cancer Society, 2006

[3] US Department of Healthand Human Services. Preventing tobacco use among young people: a report of theSurgeon General. US.

[4] Hammond D, Fong GT, Borland R, Cummings KM, McNeill A, Driezen P. Communicating risk to smokers: the impact of health warnings on cigarette packages. Am J Prev Med 2007;32:202-9.

[5] Tütün Ürünlerinin Zararlarının Önlenmesi Ve Kontrolü Hakkında Kanun. http://www.mevzuat.gov.tr/Kanunlar.aspx [Erişim Tarihi: 07.10.2012]

[6] Buzgan T, Çom S, Irmak H, Baykan H, Aydın E, Taner S. MPOWER: Tütün Salgınını Kontrol Etmeye Yönelik Politika Paketi, Sağlık Bakanlığ 1 , Ankara, 2011.

[7] WHO Framework Convention on Tobacco Control, World Health Organization 2003, Geneva.

[8] WHO Report on the Global Tobacco Epidemic, The MPOWER Package, WHO, Geneva, 2008.

[9] Bilir N, Kaplan B, Küçük Biçer B, Ararat E, Akyol M, Arslan A, et al. [Opinions of a group of high school students in Ankara on pictorial warnings on cigarette packages]. Turk Toraks Derg 2013;14:127-33.
[Article in Turkish]

[10] Vardavas CI, Connolly G, Karamanolis K, Kafatos A. Adolescents perceived effectiveness of the proposed European graphic tobacco warning labels. Eur J Public Health 2009;19:212-7.

[11] Bayrak B, Bilir N, Yardım MS, Gürkan H, Karakullukçuoğlu Z, Kaya A. [Opinions of a group of high school students about the possible impact of combined warnings to be depicted on the cigarette packages]. Turk Toraks Derg 2010;11:1-9. [Article in Turkish]

[12] Hammond D. Health warning messages on tobacco products: a review. Tob Control. 2011;20:327-37.

[13] Thrasher JF, Perez-Hernandez R, Arillo-Santillan E, BarrientosGutierrez I. [Towards informed tobacco consumption in Mexico: effect of pictorial warning labels in smokers]. Salud Publica Mex 2012;54:24253. [Article in Spanish]

[14] Önsüz MF, Topuzoğlu A, Algan A, Soydemir E, Aslan İ. [Evaluatıon of the relationship between perception of tobacco packaging warning messages and the nicotine addiction levels of smoker]. Marmara Med J 2009;22;111-22. [Article in Turkish] 